\title{
Evaluation of the conjuntival blebs using spectral domain optical coherence tomography after glaucoma surgery
}

\author{
Sara Lombardo*1, Alice Chandra Verticchio Vercellin ${ }^{1}$, Marta Raimondi ${ }^{1}$, Carmine Tinelli ${ }^{2}$, Giovanni Milano ${ }^{1}$ \\ ${ }^{1}$ University Eye Clinic, IRCCS Policlinico San Matteo, Pavia, Italy \\ ${ }^{2}$ Clinical Epidemiology and Biometric Unit, Fondazione IRCCS Policlinico San Matteo, Pavia, Italy
}

Received: February 28, 2016

Accepted: May 5, 2016

Online Published: July 18, 2016

DOI: $10.5430 /$ css.v2n4p1

URL: http://dx.doi.org/10.5430/css.v2n4p1

\begin{abstract}
Objective: Analyze the application of the spectral domain optical coherence tomography (SD-OCT), Optovue iVue, on morphofunctional assessment of filtering blebs after different types of glaucoma surgery and point out the correlation between of morphologic features of blebs (bleb-wall thickness, scleral flap profile, and presence of hyporeflective spaces and internal cavity) and intraocular pressure (IOP).

Methods: Thirty-eight eyes of thirty-two primarly open angle glaucoma patients, following three different types of glaucoma surgery (trabeculectomy with MMC 0.3\%; with the implant of the Ex-PRESS device; with the insertion of Ologen [OLO]) were recruited. Patients attended a 6-month follow-up with intermediate checks at 1 week, 1 month and 3 months. Each visit include the evaluation of bleb using both slit lamp biomicroscopy and OCT.

Results: In all patients, regardless of the type of surgery, a very significant reduction of IOP is observed after surgery. The bleb-wall thickness and the scleral flap profile are not shown to be sensitive parameters to identify the functionality of the bleb. The presence of hyporeflective spaces and of a cavity over the sclera is an important sign of bleb functionality. Among the different types of surgery, a higher percentage of blebs provided with hyporeflective spaces is in the Ex-PRESS group. In regards to the presence of a cavity over the sclera, there are no differences between the different groups. Comparing the blebs with filtering aspect at the OCT in the different groups, in the Ex-PRESS group there is a higher percentage of blebs with a filtering aspect compared to the other groups.

Conclusions: Optovue iVue, is able to show detailed superficial features of the bleb which significantly correlate with the functionality of the bleb itself.
\end{abstract}

Key Words: Glaucoma, Surgery, Bleb, Morphology, Success, Failure, Intraocular pressure, Spectral domain coherence tomography

\section{INTRODUCTION}

Glaucoma is one of the most prevalent causes of irreversible blindness in the industrialized world. ${ }^{[1]}$ Although several risk factors play a role in the pathogenesis of the disease, the mainstay of current therapies is still the reduction of the main modifiable risk factor, the intraocular pressure (IOP).

However, several patients do not achieve the required target IOP despite maximum tolerated medical therapy. In addition, they may become intolerant to medication because of adverse events thus reducing compliance. ${ }^{[2]}$ In these cases, a surgical

*Correspondence: Sara Lombardo; Email: sara.lombardo@live.it; Address: University Eye Clinic, IRCCS Policlinico San Matteo, Pavia, Italy. 
approach is warranted in order to control IOP and reduce the rate of damage progression. ${ }^{[3]}$ Trabeculectomy represents the most common and effective penetrating surgical procedure for glaucoma and is still the gold standard surgery. The purpose is to create a "guarded" fistula between the anterior chamber (AC) and the subconjunctival space. ${ }^{[4,5]}$

Antimetabolites such us 5-flurouracil (5FU) and mitomycin $\mathrm{C}$ (MMC) are frequently used in patients undergoing glaucoma filtration surgery in order to reduce postoperative conjunctival scarring and improve drainage. In order to improve safety of trabeculectomy, an alternative was introduced which involves the surgical implantation of the Ex-PRESS.

The macroscopic appearance and the microscopic features of conjunctival blebs have predictive implications for surgical outcomes of trabeculectomy. The clinical evaluation of the filtering ability of a bleb incorporates well-established parameters such as the extent, elevation, and vascularity of the conjunctiva at the site of surgery. ${ }^{[6]}$ Different bleb classification systems were proposed. ${ }^{[7-9]}$ According to these systems, a functioning bleb presents a diffuse mild elevation over the scleral flap, few conjunctival vessels, and evidence of microcysts within the conjunctival epithelium. On the other hand, failed blebs are characterized by a small superficial extension without elevation at the site of surgery (flat shape) or with a high degree of elevation with excessive and irregular vascularization (encapsulated shape).

However, these systems present some limitations such as assignment of a single vascularity grading and coarse grading scales and they are unable to describe blebs with mixed morphology. Currently, the most used grading systems, which for the most part overcome these limitations, are the Moorfields bleb grading system (MBGS) and the Indiana bleb appearance grading scale (IBAGS). ${ }^{[10]}$ The MBGS defines the bleb functionality by considering the area, height, and vascularity, whereas the IBAGS considers also the AH leakage with Seidel test.

Unfortunately, in some cases, there is no correlation between the bleb appearance and the IOP. This can lead to difficulty in assessing the filtering ability and in recognizing the signs of failure in time.

Advanced imaging diagnostic methods such as in vivo laser scanning confocal microscopy (LSCM $)^{[11-14]}$ and anterior segment-optical coherence tomography (AS-OCT) ${ }^{[15]}$ may help clinicians to assess morphology and function of blebs and to distinguish functioning from nonfunctioning blebs. These techniques can identify precocious signs of conjunctival fibrosis prior to identification with clinical assessment. LSCM was used to study the conjunctiva before and after different surgical and medical therapies for glaucoma to analyze AH outflow pathways modifications. ${ }^{[16-19]}$ In filtration surgery, LSCM proved valuable in assessing the drainage capability of conjunctival blebs by assessing microcysts density and area within the epithelium, and the collagen deposition within the stroma. ${ }^{[1-14]}$ While LSCM permits a microscopic analysis, with the advantage of analyzing tissue at a cellular level, AS-OCT allows a macroscopic analysis, useful in classifying blebs according to their morphology.

The introduction of spectral domain-OCT (SD-OCT) yielded obtaining additional or more defined information of the bleb morphology: bleb-wall, bleb-wall microcysts, bleb dimension, scleral flap and its location, scleral ostium and internal cavity. AS-OCT is shown to be able to correlate blebs structure and function and can be used to distinguish between functioning and non-functioning filtering blebs.

SD-OCT, compared to time domain (TD)-OCT, has a great resolution, an higher scanning speed (ranging from 26,000 to 40,000 A-scans per second) but a lower penetration in the tissue sample. ${ }^{[20]}$ Moreover SD-OCT platforms assess both the posterior and anterior pole of the eye (with the cornea/AS modules) and a dedicated software permits a threedimensional assessment of AC structures and conjunctival bleb. ${ }^{[6]}$

This makes SD-OCT suitable to the study of the bleb-wall characteristics, detecting the presence of optically empty cystic spaces and fibrotic processes.

The aim of our study is to analyze the application of the SD AS-OCT Optovue iVue on morphofunctional assessment of conjunctival filtering blebs after different types of glaucoma surgery and to point out the correlation between of morphologic features of blebs and IOP in order to underline the predictive implications of the AS-OCT for surgical outcomes.

\section{METHODS}

We recruited thirty-eight eyes of thirty-two patients (mean age $65.08 \pm 13.07$; M/F: 26/6), suffering from primary open angle glaucoma, who underwent a penetrating surgery because of the ineffectiveness of the medical therapy alone at the University Eye Clinic, IRCCS San Matteo Hospital, Pavia, Italy. Each study participant underwent a complete ophthalmic examination including clinical history, bestcorrected visual acuity (BCVA), slit lamp biomicroscopy of the AS, gonioscopy, Goldmann applanation tonometry, central cornea ultrasonic pachimetry and ophthalmoscopy of the posterior segment using a $+90 \mathrm{D}$ lens. The research adhered to the tenets of the Declaration of Helsinki. 
Informed consent was obtained from each subject after having been explained the nature of the study. BCVA, IOP and eye drop therapy (number of anti-glaucomatous drugs and years of therapy) were not part of the inclusion/exclusion criteria.

Participants were excluded if they had any retinal disease, non glaucomatous optic neuropathy or any significant coexisting systemic disease that could affect the eye and the postsurgical fibrotic processes. The patients underwent different surgical procedures: in some cases trabeculectomy with the addition of MMC $0.3 \%$ was performed. In others, Ex-PRESS 200 device (Alcon Laboratories, Fort Worth, Texas, USA) with the addition of MMC $0.3 \%$ was implanted. In others, Ologen (OLO) collagen matrix (Aeon Astron Europe BV, Leiden, the Netherlands) was inserted.

The outcome of gonioscopy was determinant for the choice of the type of surgery: widely open angles (grade $\geq 3$ for Shaffer angle classification) without significant peripheral anterior synechiae (PAS) were selected for trabeculectomy with MMC while moderately open angles (grade 2 for Shaffer angle classification) and/or open angles with significant PAS were treated by Ex-PRESS implant with MMC, in a proper placement to avoid areas of PAS. The insertion of OLO was reserved for older patients, in which the fibrotic processes are often less pronounced.

Depending on the type of surgery, patients were divided into 3 groups:

- Group 1 (mean age $63.36 \pm 13.31$; M/F: 21/4): trabeculectomy with MMC;

- Group 2 (mean age $60.33 \pm 12.14 ;$ M/F: 5/1): ExPRESS 200 with MMC;

- Group 3 (mean age $75.29 \pm 8.14$; M/F: 3/4): OLO without MMC.

Patients attended a 6-month follow-up with intermediate checks at 1 week, 1 month and 3 months after surgery. At each visit the patient underwent complete eye examination, including Goldmann applanation tonometry and the evaluation of bleb using both slit lamp biomicroscopy and Optovue RTVue 100 SD-OCT (Optovue, Inc., Fremont, CA).

The RTVue's Fourier or SD-OCT technology uses low coherence interferometry to detect light echoes, relying on a spectrometer charge-coupled device (CCD) camera. The RTVue utilizes light at $840 \mathrm{~nm}$ wavelenght and measures all echoes of light simultaneously - compared to sequentially, in the case of TD-OCT - improving sensitivity and imaging speed. In addition it features a parallel acquisition design that helps to obtain a whole axial scan by simultaneously capturing 2,048 pixels, providing a high-definition image in 0.04 $\mathrm{s}$ without creating significant motion errors. The scanning speed is 26,000 A-scans per second, 65 times faster than the scanning capability of TD-OCT. The cornea/AS module of RTVue allows for AS and corneal imaging with a resolution of $5 \mu \mathrm{m} .^{[15]}$

Optovue iVue OCT is also compact, portable, and easy to use. Dedicated software permits a three-dimensional assessment of the AC structures and conjunctival bleb, using the specific lens for the AS and the irido-corneal angle program that performs linear scans with an orientation from $0^{\circ}$ to $180^{\circ}$.

The examination is done with the patient in a sitting position. As it is a non-contact procedure, topical anesthesia is not required. Wide palpebral apertures are required to get a scan unobstructed by the eyelids. This is particularly important for vertical scans. The patient is asked to look down and the upper eyelid is manually raised by the operator. The images of the conjunctival bleb were obtained using linear scans covering an area of $180^{\circ}$ and including the scleral flap, the internal ostium and the point of maximum elevation of the bleb.

In regards to the functionality of the bleb, we considered more qualitative rather than quantitative features of the bleb: the thickness of the bleb-wall (which were assessed subjectively and compared to the appearance of the conjunctivalepiscleral tissue in a normal subject), the presence of inner hyporeflective spaces, the internal cavity (which is defined as the hyporeflective space immediately over the sclera or over the scleral flap), the scleral flap profile, the presence of hyporeflective spaces under the scleral tissue and the presence of the internal ostium. The OCT images are analyzed by the same observer, who is blind for the type of surgery.

For the purposes of the study, IOP and hypotonic treatment are the clinical parameters that are taken into account in the follow-up in order to evaluate the results of surgery. We considered surgical success as the presence of IOP $<21 \mathrm{mmHg}$ after six months from surgery in the absence of a hypotonic therapy.

At the different times of follow-up and in different groups, we took into account two parameters and compared them: the bleb qualitative features and the IOP values.

The Shapiro-Wilk test was used to test the normal distribution of quantitative variables. When quantitative variables were normally distributed, the results were expressed as the mean value and $\mathrm{SD}$, otherwise median and interquartile range (IQR; $25^{t h}-75^{t h}$ percentile) were reported. Qualitative variables were summarized as counts and percentages. The associations between surgery groups, bleb morphological features, IOP, therapies and changes over time were assessed by linear 
regression univariate and multivariate models for repeated measures. $p<.05$ was considered statistically significant and all tests were two-sided. Data analysis was performed with STATA statistical package (release 14, 2015, Stata Corporation, College Station, Texas, USA).

\section{Results}

We analyzed thirty-eight eyes of thirty-two patients who underwent glaucoma surgery. Trabeculectomy with MMC was performed in 25 eyes (65.79\%, Group 1), Ex-PRESS 200 implant with MMC in 6 eyes (15.79\%, Group 2), collagen matrix insertion (OLO) and no MMC in 7 eyes $(18.42 \%$, Group 3). A higher mean age was found in Group 3 compared to Group 1 and 2 (value at the limit of the statistical significance, $p=.093$ ). There was less of a need for antimetabolites in elder patients since their tissues are less reactive.

In the preoperative visit, the mean IOP was 25.53 $( \pm 6.47) \mathrm{mmHg}$ and the mean number of anti-glaucomatous drops was 2.97 ( \pm 0.74 ); in Group 1, the mean preoperative IOP was $24.83( \pm 6.54) \mathrm{mmHg}$ and the mean number of anti-glaucomatous drops was $2.96( \pm 0.69)$; in Group 2 , the mean preoperative IOP was $29.3( \pm 8.24) \mathrm{mmHg}$ and the mean number of anti-glaucomatous drops was 3.17 $( \pm 0.98)$; in Group 3, the mean preoperative IOP was 24.5 $( \pm 2.66) \mathrm{mmHg}$ and the mean number of anti-glaucomatous drops was $2.83( \pm 0.75)$. At the $\mathrm{T} 1$ visit, realized in median 6 days (IQR: $3-9$ ) after the surgical treatment, only 1 patient of the Group 3 was under anti-glaucomatous drops and the mean total IOP was $9.79( \pm 3.18) \mathrm{mmHg}, 10.06$ $( \pm 2.64) \mathrm{mmHg}$ in Group 1, $8.67( \pm 4.08) \mathrm{mmHg}$ in Group 2, and $10.14( \pm 3.76) \mathrm{mmHg}$ in Group 3. At the T2 visit, realized in median 22.5 days (IQR: 17-29) after T1, only 1 patient from Group 3 was under anti-glaucomatous drops with only 1 active principle and the mean total IOP was 11.7 $( \pm 3.76) \mathrm{mmHg}$ : $11.53( \pm 4.10) \mathrm{mmHg}$ in Group $1,11.4$ $( \pm 3.13) \mathrm{mmHg}$ in Group 2, and $12.5( \pm 3.56) \mathrm{mmHg}$ in Group 3. At the T3 visit, 3 months after the surgical treatment and in median 64 days (IQR: 56-72) after T2, 3 patients ( 2 in Group 1 and 1 in Group 3) started an anti-glaucomatous therapy. The mean total IOP was $13( \pm 3.16) \mathrm{mmHg}: 12.7$ $( \pm 3.21) \mathrm{mmHg}$ in Group $1,12.6( \pm 2.51) \mathrm{mmHg}$ in Group 2 , and $14.5( \pm 3.51) \mathrm{mmHg}$ in Group 3. At the last visit, T4, 6 months after the surgical treatment and in median 96 days (IQR: 71-103) after T3, an additional 3 patients started an anti-glaucomatous therapy. The mean total IOP was 12.59 $( \pm 4.39) \mathrm{mmHg}: 12.22( \pm 5.12) \mathrm{mmHg}$ in Group $1,12.67$ $( \pm 2.52) \mathrm{mmHg}$ in Group 2, and $13.67( \pm 2.58) \mathrm{mmHg}$ in Group 3.

The trend of the IOP during follow-up did not seem to differ 4 in a statistically significant way between the three types of surgery (see Figures 1-3).

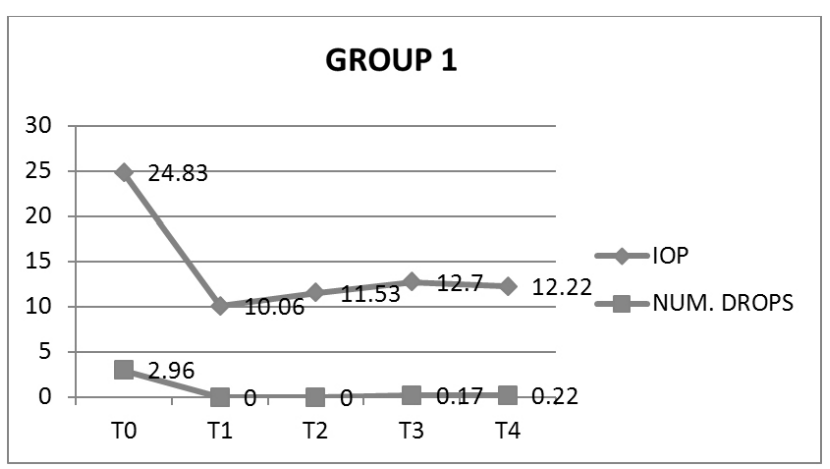

Figure 1. IOP and number of glaucomatous drugs in the different follow-up points in Group 1

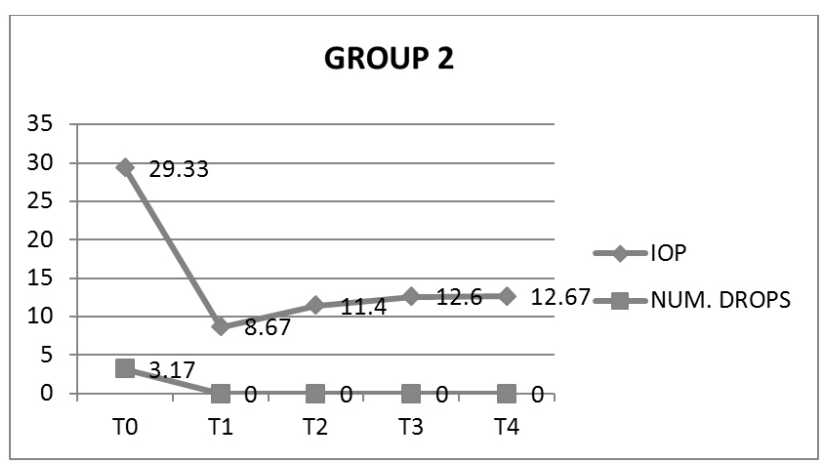

Figure 2. IOP and number of glaucomatous drugs in the different follow-up points in Group 2

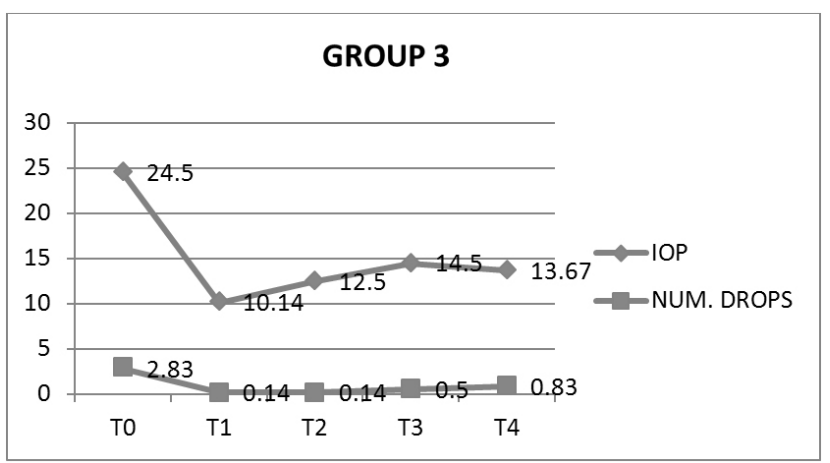

Figure 3. IOP and number of glaucomatous drugs in the different follow-up points in Group 3

The surgical treatment was unsuccessful in 6 patients (15.79\%), who needed to start an anti-glaucomatous therapy during the follow up period at different points: 4 patients in Group 1 and 2 in Group 3. In these patients, the preoperative IOP was $24( \pm 2.35) \mathrm{mmHg}$ with an anti-glaucomatous therapy with $3.40( \pm 0.55)$ active principles; in the postoperative visits the IOP was $10.5( \pm 3.42) \mathrm{mmHg}$ at $\mathrm{T} 1,12.75$ $( \pm 3.20) \mathrm{mmHg}$ at $\mathrm{T} 2,15.33( \pm 1.51) \mathrm{mmHg}$ at $\mathrm{T} 3$ and 
$15.2( \pm 4.55) \mathrm{mmHg}$ at $\mathrm{T} 4$ with a mean number of antiglaucomatous drugs of $0.25( \pm 0.50)$ at $\mathrm{T} 1,0.20( \pm 0.45)$ at $\mathrm{T} 2,1.17( \pm 1.33)$ at $\mathrm{T} 3$, and $1.80( \pm 0.84)$ at $\mathrm{T} 4$.

Thirty-two eyes (84.21\%) were surgically successful, with a mean IOP $<21 \mathrm{mmHg}$ with no anti-glaucomatous treat- ment. In these patients, the preoperative IOP was 25.77 $( \pm 6.90) \mathrm{mmHg}$ with $2.90( \pm 0.75)$ anti-glaucomatous active principles. The IOP in the follow-up visits was 9.68 $( \pm 3.20) \mathrm{mmHg}$ at $\mathrm{T} 1,11.54( \pm 3.87) \mathrm{mmHg}$ at $\mathrm{T} 2,12.5$ $( \pm 3.21) \mathrm{mmHg}$ at $\mathrm{T} 3$, and $12( \pm 4.23) \mathrm{mmHg}$ at $\mathrm{T} 4$ (see Table 1).

Table 1. IOP and number of glaucomatous drugs in the different follow up points in the total population and in the different groups $(1,2,3$, surgical successes and surgical failures)

\begin{tabular}{|c|c|c|c|c|c|c|c|c|c|c|}
\hline \multirow{2}{*}{ Groups } & \multicolumn{5}{|c|}{ IOP $^{*}$} & \multicolumn{5}{|c|}{ Anti-glaucomatous drops ${ }^{* *}$} \\
\hline & T0 & T1 & $\mathbf{T} 2$ & T3 & T4 & T0 & T1 & $\mathbf{T} 2$ & T3 & T4 \\
\hline $\begin{array}{l}\text { Total } \\
\text { Population }\end{array}$ & $25.53 \pm 6.47$ & $9.79 \pm 3.18$ & $11.70 \pm 3.76$ & $13 \pm 3.16$ & $12.59 \pm 4.39$ & $2.97 \pm 0.74$ & $0.03 \pm 0.18$ & $0.03 \pm 0.18$ & $0.21 \pm 0.69$ & $0.33 \pm 0.78$ \\
\hline Group 1 & $24.83 \pm 6.54$ & $10.06 \pm 2.64$ & $11.53 \pm 4.10$ & $12.7 \pm 3.21$ & $12.22 \pm 5.12$ & $2.96 \pm 0.69$ & $0 \pm 0$ & $0 \pm 0$ & $0.17 \pm 0.58$ & $0.22 \pm 0.55$ \\
\hline Group 2 & $29.33 \pm 8.24$ & $8.67 \pm 4.08$ & $11.40 \pm 3.13$ & $12.6 \pm 2.51$ & $12.67 \pm 2.52$ & $3.17 \pm 0.98$ & $0 \pm 0$ & $0 \pm 0$ & $0 \pm 0$ & $0 \pm 0$ \\
\hline Group 3 & $24.50 \pm 2.66$ & $10.14 \pm 3.76$ & $12.50 \pm 3.56$ & $14.5 \pm 3.51$ & $13.67 \pm 2.58$ & $2.83 \pm 0.75$ & $0.14 \pm 0.38$ & $0.14 \pm 0.38$ & $0.50 \pm 1.22$ & $0.83 \pm 1.33$ \\
\hline $\begin{array}{l}\text { Successful } \\
\text { Group }\end{array}$ & $25.77 \pm 6.90$ & $9.68 \pm 3.20$ & $11.54 \pm 3.87$ & $12.5 \pm 3.21$ & $12 \pm 4.23$ & $2.90 \pm 0.75$ & $0 \pm 0$ & $0 \pm 0$ & $0 \pm 0$ & $0 \pm 0$ \\
\hline Failure Group & $24 \pm 2.35$ & $10.5 \pm 3.42$ & $12.75 \pm 3.20$ & $15.33 \pm 1.51$ & $15.2 \pm 4.55$ & $3.40 \pm 0.55$ & $0.25 \pm 0.50$ & $0.20 \pm 0.45$ & $1.17 \pm 1.33$ & $1.80 \pm 0.84$ \\
\hline
\end{tabular}

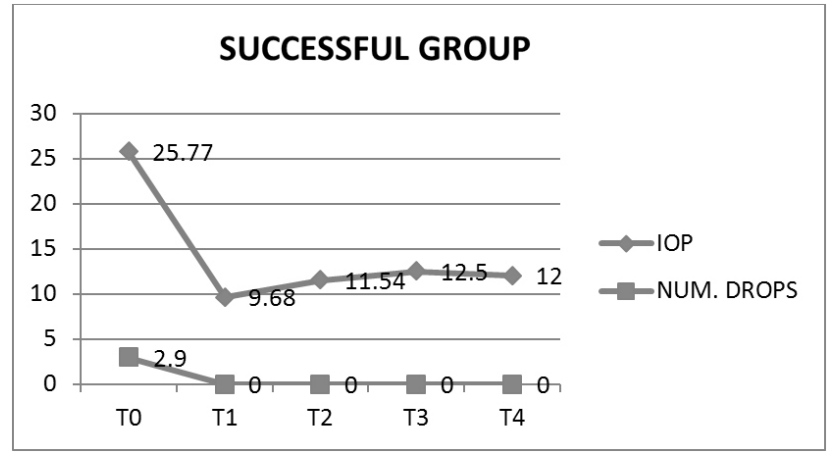

Figure 4. IOP and number of glaucomatous drugs in the different follow-up points in successful group

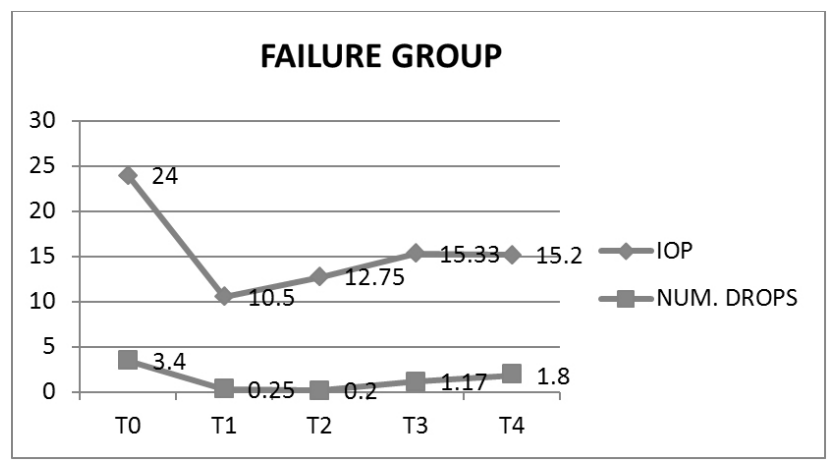

Figure 5. IOP and number of glaucomatous drugs in the different follow-up points in failure group

The trend of the IOP during follow-up did not differ significantly between the three types of surgery, while a statistical significant difference was found in postoperative IOP trend comparing the group of surgical successes to the group of failures ( $p=.004)$ (see Figures 4 and 5).

Concerning the filtration morphological features visualized at the SD-OCT, in any scan it was possible to visualize structures under the scleral flap; for this reason, it has not been possible to analyze the presence of hyporeflective sub-flap space and internal ostium. The following morphological features of the bleb have been analyzed in the OCT scans: wall thickness, discrete hyporeflective spaces in the wall, bleb cavity, and scleral flap (see Table 2).

No statistical significant difference was found comparing the bleb's morphological features in the different points of follow up.

In regards to the thickness of the wall, a thinner wall was found in Group 3 compared to Group 1 (61.67\% vs. 96.27\%; $p=.035)$, and a thicker wall in Group 2 compared to Group 1 (value at the limit of the statistical significance, $p=.078$ ).

No statistically significant difference was found comparing the group of surgical successes to the failures.

In Group 2, a higher number of scans with discrete hyporeflective spaces in the wall were found compared to other groups (100\% in Group 2 vs. $88.71 \%$ in Group 1; $p=.047)$. In the group of patients who needed to start an anti-glaucomatous therapy during the follow-up period, the percentage of hyporeflective spaces in the wall at the OCT was lower compared to the surgical success group (25\% vs. $100 \% ; p=.000)$. 
Table 2. Bleb morphological feature in the different follow up points in the total population and in the different groups $(1,2$, 3 , surgical successes and surgical failures)

\begin{tabular}{|c|c|c|c|c|c|c|c|c|c|c|}
\hline \multirow{2}{*}{ Groups } & \multicolumn{5}{|c|}{ Thick Bleb-Wall } & \multicolumn{5}{|c|}{ Hyporeflective Spaces } \\
\hline & T1 & $\mathbf{T} 2$ & T3 & T4 & Tot. & T0 & T1 & $\mathbf{T} 2$ & T3 & Tot. \\
\hline $\begin{array}{l}\text { Total } \\
\text { Population }\end{array}$ & $\begin{array}{c}25 / 27^{*} \\
(92,53 \%)^{* *}\end{array}$ & $\begin{array}{c}24 / 26 \\
(92,31 \%)\end{array}$ & $\begin{array}{c}29 / 32 \\
(90,63 \%)\end{array}$ & $\begin{array}{c}24 / 26 \\
(92,31 \%)\end{array}$ & $91.96 \%{ }^{* *}$ & $\begin{array}{c}26 / 27 \\
(96,3 \%)\end{array}$ & $\begin{array}{c}23 / 26 \\
(88,46 \%)\end{array}$ & $\begin{array}{c}27 / 32 \\
(84,38 \%)\end{array}$ & $\begin{array}{c}22 / 26 \\
(84,62 \%)\end{array}$ & $88.44 \%$ \\
\hline Group 1 & $\begin{array}{l}19 / 20 \\
(95 \%)\end{array}$ & $\begin{array}{c}18 / 18 \\
(100 \%)\end{array}$ & $\begin{array}{c}22 / 23 \\
(95,65 \%)\end{array}$ & $\begin{array}{c}17 / 18 \\
(94,44 \%)\end{array}$ & $96.27 \%$ & $\begin{array}{c}20 / 20 \\
(100 \%)\end{array}$ & $\begin{array}{c}16 / 18 \\
(88,89 \%)\end{array}$ & $\begin{array}{c}19 / 23 \\
(82,61 \%)\end{array}$ & $\begin{array}{c}15 / 18 \\
(83,33 \%)\end{array}$ & $88.71 \%$ \\
\hline Group 2 & $\begin{array}{c}4 / 4 \\
(100 \%)\end{array}$ & $\begin{array}{c}4 / 4 \\
(100 \%)\end{array}$ & $\begin{array}{c}5 / 5 \\
(100 \%)\end{array}$ & $\begin{array}{c}3 / 3 \\
(100 \%)\end{array}$ & $100 \%$ & $\begin{array}{c}4 / 4 \\
(100 \%)\end{array}$ & $\begin{array}{c}4 / 4 \\
(100 \%)\end{array}$ & $\begin{array}{c}5 / 5 \\
(100 \%)\end{array}$ & $\begin{array}{c}3 / 3 \\
(100 \%)\end{array}$ & $100 \%$ \\
\hline Group 3 & $\begin{array}{c}2 / 3 \\
(66,67 \%)\end{array}$ & $\begin{array}{c}2 / 4 \\
(50 \%)\end{array}$ & $\begin{array}{c}2 / 4 \\
(50 \%)\end{array}$ & $\begin{array}{c}4 / 5 \\
(80 \%)\end{array}$ & $61.67 \%$ & $\begin{array}{c}2 / 3 \\
(66,67 \%)\end{array}$ & $\begin{array}{c}3 / 4 \\
(75 \%)\end{array}$ & $\begin{array}{c}3 / 4 \\
(75 \%)\end{array}$ & $\begin{array}{c}4 / 5 \\
(80 \%)\end{array}$ & $74.17 \%$ \\
\hline $\begin{array}{l}\text { Successful } \\
\text { Group }\end{array}$ & $\begin{array}{c}22 / 23 \\
(95,65 \%)\end{array}$ & $\begin{array}{c}21 / 22 \\
(95,45 \%)\end{array}$ & $\begin{array}{c}25 / 27 \\
(92,59 \%)\end{array}$ & $\begin{array}{c}22 / 22 \\
(100 \%)\end{array}$ & $95.92 \%$ & $\begin{array}{c}23 / 23 \\
(100 \%)\end{array}$ & $\begin{array}{c}22 / 22 \\
(100 \%)\end{array}$ & $\begin{array}{c}27 / 27 \\
(100 \%)\end{array}$ & $\begin{array}{c}22 / 22 \\
(100 \%)\end{array}$ & $100 \%$ \\
\hline $\begin{array}{l}\text { Failure } \\
\text { Group }\end{array}$ & $\begin{array}{c}3 / 4 \\
(75 \%)\end{array}$ & $\begin{array}{c}3 / 4 \\
(75 \%)\end{array}$ & $\begin{array}{c}3 / 5 \\
(60 \%)\end{array}$ & $\begin{array}{c}2 / 4 \\
(50 \%)\end{array}$ & $62.50 \%$ & $\begin{array}{c}3 / 4 \\
(75 \%)\end{array}$ & $\begin{array}{c}1 / 4 \\
(25 \%)\end{array}$ & $\begin{array}{c}0 / 5 \\
(0 \%)\end{array}$ & $\begin{array}{c}0 / 4 \\
(0 \%)\end{array}$ & $25 \%$ \\
\hline Groups & \multicolumn{5}{|c|}{ Cavity Over The Sclera } & \multicolumn{5}{|c|}{ Scleral Flap } \\
\hline $\begin{array}{l}\text { Total } \\
\text { Population }\end{array}$ & $\begin{array}{c}26 / 27 \\
(96,3 \%)\end{array}$ & $\begin{array}{c}24 / 26 \\
(92,31 \%)\end{array}$ & $\begin{array}{c}29 / 32 \\
(90,63 \%)\end{array}$ & $\begin{array}{c}23 / 26 \\
(88,46 \%)\end{array}$ & $91.92 \%$ & $\begin{array}{c}26 / 27 \\
(96,3 \%)\end{array}$ & $\begin{array}{c}23 / 26 \\
(88,46 \%)\end{array}$ & $\begin{array}{c}27 / 32 \\
(84,38 \%)\end{array}$ & $\begin{array}{c}22 / 26 \\
(84,62 \%)\end{array}$ & $88.44 \%$ \\
\hline Group 1 & $\begin{array}{c}20 / 20 \\
(100 \%)\end{array}$ & $\begin{array}{c}17 / 18 \\
(94,44 \%)\end{array}$ & $\begin{array}{c}21 / 23 \\
(91,30 \%)\end{array}$ & $\begin{array}{c}16 / 18 \\
(88,89 \%)\end{array}$ & $93.66 \%$ & $\begin{array}{c}20 / 20 \\
(100 \%)\end{array}$ & $\begin{array}{c}16 / 18 \\
(88,89 \%)\end{array}$ & $\begin{array}{c}19 / 23 \\
(82,61 \%)\end{array}$ & $\begin{array}{c}15 / 18 \\
(83,33 \%)\end{array}$ & $88.71 \%$ \\
\hline Group 2 & $\begin{array}{c}4 / 4 \\
(100 \%)\end{array}$ & $\begin{array}{c}4 / 4 \\
(100 \%)\end{array}$ & $\begin{array}{c}5 / 5 \\
(100 \%)\end{array}$ & $\begin{array}{c}3 / 3 \\
(100 \%)\end{array}$ & $100 \%$ & $\begin{array}{c}4 / 4 \\
(100 \%)\end{array}$ & $\begin{array}{c}4 / 4 \\
(100 \%)\end{array}$ & $\begin{array}{c}5 / 5 \\
(100 \%)\end{array}$ & $\begin{array}{c}3 / 3 \\
(100 \%)\end{array}$ & $100 \%$ \\
\hline Group 3 & $\begin{array}{c}2 / 3 \\
(66,67 \%)\end{array}$ & $\begin{array}{c}3 / 4 \\
(75 \%)\end{array}$ & $\begin{array}{c}3 / 4 \\
(75 \%)\end{array}$ & $\begin{array}{c}4 / 5 \\
(80 \%)\end{array}$ & $74.17 \%$ & $\begin{array}{c}2 / 3 \\
(66,67 \%)\end{array}$ & $\begin{array}{c}3 / 4 \\
(75 \%)\end{array}$ & $\begin{array}{c}3 / 4 \\
(75 \%)\end{array}$ & $\begin{array}{c}4 / 5 \\
(80 \%)\end{array}$ & $74.17 \%$ \\
\hline $\begin{array}{l}\text { Successful } \\
\text { Group }\end{array}$ & $\begin{array}{c}23 / 23 \\
(100 \%)\end{array}$ & $\begin{array}{c}22 / 22 \\
(100 \%)\end{array}$ & $\begin{array}{c}27 / 27 \\
(100 \%)\end{array}$ & $\begin{array}{c}22 / 22 \\
(100 \%)\end{array}$ & $100 \%$ & $\begin{array}{c}23 / 23 \\
(100 \%)\end{array}$ & $\begin{array}{c}22 / 22 \\
(100 \%)\end{array}$ & $\begin{array}{c}27 / 27 \\
(100 \%)\end{array}$ & $\begin{array}{c}22 / 22 \\
(100 \%)\end{array}$ & $100 \%$ \\
\hline $\begin{array}{l}\text { Failure } \\
\text { Group }\end{array}$ & $\begin{array}{c}3 / 4 \\
(75 \%)\end{array}$ & $\begin{array}{c}2 / 4 \\
(50 \%)\end{array}$ & $\begin{array}{c}2 / 5 \\
(40 \%)\end{array}$ & $\begin{array}{c}1 / 4 \\
(25 \%)\end{array}$ & $47.50 \%$ & $\begin{array}{c}3 / 4 \\
(75 \%)\end{array}$ & $\begin{array}{c}1 / 4 \\
(25 \%)\end{array}$ & $\begin{array}{c}0 / 5 \\
(0 \%)\end{array}$ & $\begin{array}{c}0 / 4 \\
(0 \%)\end{array}$ & $25 \%$ \\
\hline
\end{tabular}

${ }^{*}$ number, ${ }^{* *}$ percentage

There was not a statistical significant difference regarding the presence of a supra-scleral cavity in Groups 1,2, and 3, but the percentage of scan with a supra-scleral cavity was lower in the surgical failures group compared to the surgical successes group $(47.5 \%$ vs. $100 \%, p=.005)$.

It was not been possible to analyze the profile of the scleral flap in a higher number of patients of Group 3 compared to the other groups ( $0 \%$ in Group 3 vs. $69.01 \%$ in Group 1, $p=.000)$; no statistical difference in the visualization of the scleral flap has been found comparing the group of surgical failures to the one of successes.

Similar to the literature and our experience, the morphological aspect of the filtering bleb in the SD-OCT scan is characterized by the presence of a thick wall and of hyporeflective spaces or micro cysts in the conjunctival/episcleral tissue with or without the visualization of a real supra-scleral cavity. Difficulty is caused by the low penetration and by the visualization defendant of the area of the bleb analyzed (see Figure 6).

Conversely, the features of a non-filtering bleb at the OCT include the presence of hypereflective spaces in the wall which is thin and without any hyporeflective spaces or microcysts (see Figure 7).
We analyzed the presence of a filtering bleb's aspect in the OCT scan in the population studied, distinguishing different groups considering the type of surgical treatment (Group 1,2 , and 3 ) and the success or failure of the surgery in the different moment during the follow-up (T1, T2, T3 and T4) (see Table 3).

Comparing the 3 groups, we saw that Group 2 presented with higher percentage of blebs with filtering aspect $(100 \%$ in Group 2 vs. 88.71\% in Group 1; $p=.047$ ).

A statistical significant difference was found in the aspect of the bleb comparing the surgical successes and failures $(100 \%$ vs. $25 \% ; p=.000$ ).

Also, in this case, a non-statistical significant difference was found in the percentages of blebs with a filtering aspect in the different moments of the follow-up.

\section{Discussion}

Surgical procedures for glaucoma lead to an elevation of the conjunctiva at the site of surgery, which is commonly referred to as a filtering bleb. A filtering bleb is considered a cornerstone of IOP control after glaucoma filtration surgery. ${ }^{[21-24]}$ This structure allows AH to drain from the $\mathrm{AC}$ into the subconjunctiva, lowering the IOP. 


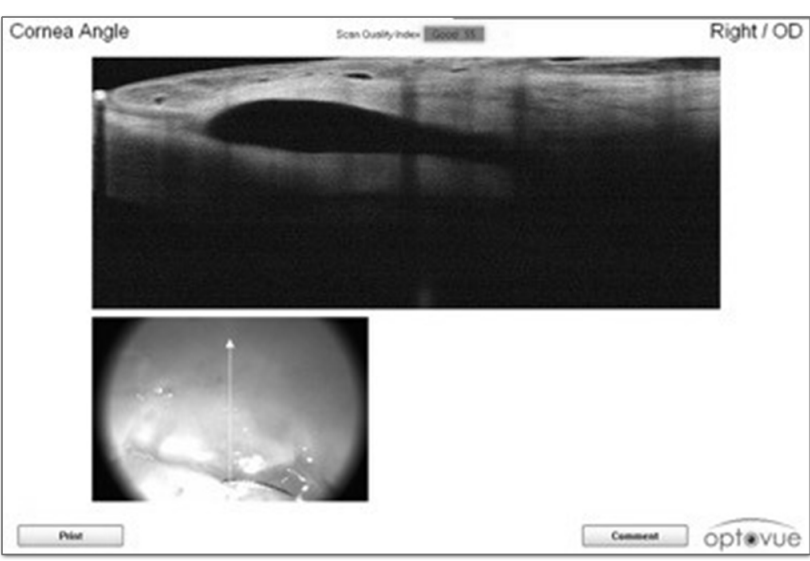

Figure 6. Morphological aspect of a filtering bleb in SD-OCT

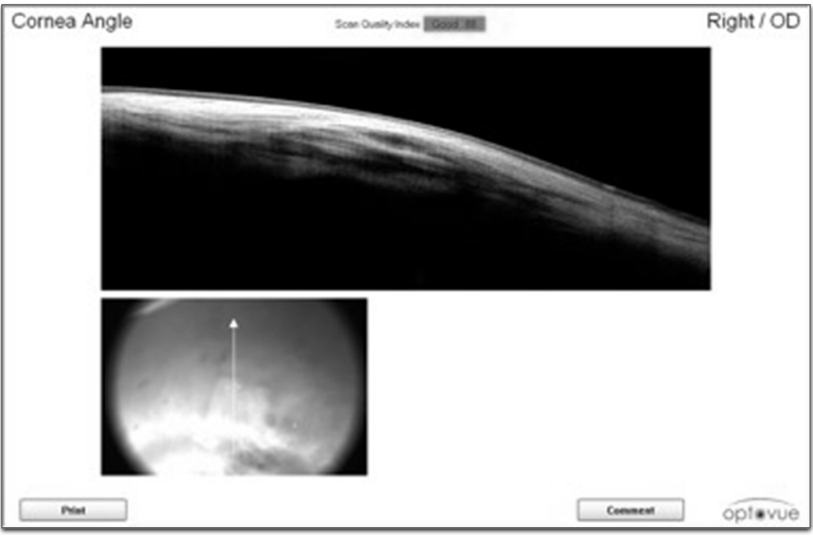

Figure 7. Morphological aspect of a non-filtering bleb in SD-OCT

Table 3. Number and percentages of eye presenting filtering bleb's aspect in OCT scans in the different follow up points in the total population and in the different groups $(1,2,3$, surgical successes and surgical failures)

\begin{tabular}{lccccc}
\hline \multirow{2}{*}{ Groups } & \multicolumn{5}{c}{ Filtering Bleb } \\
\cline { 2 - 6 } & T1 & T2 & T3 & T4 & Tot. \\
\hline Total & $26 / 27^{*}$ & $23 / 26$ & $27 / 32$ & $22 / 26$ & \multirow{2}{*}{$88.44 \%^{* *}$} \\
Population & $(96,30 \%)^{* *}$ & $(88,46 \%)$ & $(84,38 \%)$ & $(84,62 \%)$ & \\
Group 1 & $20 / 20$ & $16 / 18$ & $19 / 23$ & $15 / 18$ & $88.71 \%$ \\
& $(100 \%)$ & $(88,89 \%)$ & $(82,61 \%)$ & $(83,33 \%)$ & \\
Group 2 & $4 / 4$ & $4 / 4$ & $5 / 5$ & $3 / 3$ & $100 \%$ \\
& $(100 \%)$ & $(100 \%)$ & $(100 \%)$ & $(100 \%)$ & \\
Group 3 & $2 / 3$ & $3 / 4$ & $3 / 4$ & $4 / 5$ & $74.17 \%$ \\
Successful & $(66,67 \%)$ & $(75 \%)$ & $(75 \%)$ & $(80 \%)$ & \\
Group & $23 / 23$ & $22 / 22$ & $27 / 27$ & $22 / 22$ & $100 \%$ \\
Failure & $100 \%)$ & $(100 \%)$ & $(100 \%)$ & $(100 \%)$ & \\
Group & $3 / 4$ & $1 / 4$ & $0 / 5$ & $0 / 4$ & $25 \%$ \\
\hline "number; ${ }^{* *}$ percentage & $(75 \%)$ & $(25 \%)$ & $(0 \%)$ & $(0 \%)$ & \\
\hline
\end{tabular}

The morphology of the bleb is considered an important clinical parameter that has predictive implications for its functionality.

Published by Sciedu Press
In our study, we wanted to analyze, using SD-OCT (Optovue RTVue), the conjunctival blebs following three different types of glaucoma surgery: trabeculectomy with MMC $0.3 \%$ (Group 1), with the implant of the Ex-PRESS 200 device and MMC $0.3 \%$ (Group 2) and with the insertion of OLO collagen matrix (Group 3). In all patients, regardless of the type of surgery and its success, a very significant reduction of preoperative IOP is observed after the surgery. The trend of IOP in the follow-up does not statistically significantly differ between the three types of surgery. However, the difference in the trend of postoperative IOP is significant between surgical success and failures, as proven by those patients who began a topical therapy in our study.

As previously reported in the literature, SD-OCT, compared to TD-OCT, has a great resolution but a lower penetration in the tissue sample. ${ }^{[20]}$

This limitation was also shown in our study: in any scan we could overcome the scleral flap in depth, getting no information about the presence of hyporeflective spaces under the sclera and the presence of internal ostium and its patency.

On the other hand, the high resolution allows us to evaluate the bleb-wall thickness, the scleral flap profile, and the presence of hyporeflective spaces and internal cavity. In our sample, the wall thickness is not shown to be a sensitive parameter to identify the functionality of the bleb. Instead, a difference in the wall thickness is found, depending on the type of surgical procedure.

Compared with the group of patients undergoing trabeculectomy with MMC (Group 1), the bleb-walls with OLO insert (Group 3) are thinner and those with Ex-PRESS implant (Group 2) are thicker. As seen in the literature, a thick wall is a sign of increased bleb functionality; this is consistent with our findings: those with Ex-PRESS implant (Group 2) had a surgical success rate of $100 \%$.

Our results show that the presence of hyporeflective spaces and of a cavity over the sclera is an important sign of bleb functionality. The number of bleb with hyporeflective spaces and cavities over the sclera statistically significantly differ between success and failure.

Among the different types of surgery, we observed a higher percentage of blebs provided with hyporeflective spaces in the Ex-PRESS group (Group 2). In regards to the presence of a cavity over the sclera, there are no differences between the different groups.

It should be noted that the acquisition of scans showing a real cavity was not always possible. This difficulty can be explained by the low penetration of SD-OCT and by the vari- 
ability due to the localization of the scan. The area used for the filtration is, in fact, larger than the area which is occupied by the exposed conjunctiva and can be evaluated by OCT scans.

The scleral flap profile has not proven to be a sign of bleb functionality. This result is most likely due to the small number of scans in which the scleral flap was displayed because of the low penetration of the SD system.

For the same reason, in scans in which the scleral flap was observed, it has not been possible to analyze the profile and the presence of the spaces below, which are both parameters of bleb functionality. Specifically, in any bleb in Group 3, the scleral flap was not identified because of the presence of collagen tissue within the cavity over the sclera, which mask anything below.

Considering previous research, it has been shown that in the population studied the OCT aspect of a filtering bleb should take into account the presence of hyporeflective spaces, of a cavity over the sclera and, to a lesser extent, the thickness of the cavity. It has been proven that the OCT aspect of the bleb is very sensitive in identifying really filtering blebs. Comparing the blebs with filtering aspect at the OCT in the different groups according to the surgical treatment, we can see that in Group 2, there is a higher percentage of blebs with a filtering aspect compared to the other groups.

From our analysis, the patients who underwent filtering surgical treatment with Ex-PRESS implant present functioning blebs in a higher percentage compared to other patients, also shown in the OCT scans. This can be explained by the different type of flow through the scleral canal, which is regular in the patients with the Express implant and turbulent in patient who underwent trabeculectomy. ${ }^{[6]}$ In addition, as it has been shown in the literature, ${ }^{[6]}$ the position of the Ex-PRESS valve is important in predicting the success or failure of the bleb. In our sample, in the OCT scan of 5 patients, we saw the valve, located under the scleral flap and drawing out from the anterior chamber. However, it was not possible to visualize it in its entirety. This limitation did not allow us to evaluate its position compared to the limbus.

The functionality of the blebs with OLO insertion is comparable with the functionality of the blebs after Trabeculectomy with MMC $0.3 \%$.

In our follow-up, we did not found any statistical significant difference in the OCT features. This means that after a few days from the surgical treatment, the bleb successful in reducing the IOP has an OCT aspect very similar to the bleb after 6 months from the surgery. OCT can give indications about the effectiveness of the bleb not only in the moment in which the scan is made but also the future efficacy, predicting the cases in which it will be necessary to add a anti-glaucomatous therapy in order to adequately control the IOP.

The principal limitations of our study are the small size of the sample and the great difference as a number of cases between the three groups (25/6/7) and between success and failure (6/38). This can reduce the significance of the statistical results that we found. The choice of the type of surgery was determined by the angle condition at gonioscopy, which is an operator-dependent procedure, and by the characteristics of patient (first of all age); this explains the difference as a number of cases between the 3 groups. The presence of blebs with a lower filtering aspect at the OCT in the group of failures can also be explained by the higher number of active principles used before and after the surgical treatment in these patients compared to those in the group of successes ( $3.0 \pm 0.55$ vs. $2.90 \pm 0.75$ at $\mathrm{T} 0$ ). The anti-glaucomatous drugs, in fact, cause conjunctival alterations that could affect the bleb aspect at the OCT.

\section{Conclunsions}

In conclusion, SD-OCT, and in particular Optovue iVue, is able to show detailed superficial features of the bleb which significantly correlate with the functionality of the bleb itself.

\section{CONFlicts OF INTEREST Disclosure}

The authors declare that they have no competing interests.

\section{REFERENCES}

[1] Kingman S. Glaucoma is the second leading cause of blindness globally. Bull World Healthy Organ. 2004; 82(11): 887-888. PMid: 15640929.

[2] Friedman DS, Okeke CO, Jampel HD, et al. Risk factors for poor adherence to eyedrops in electronically monitored patients with glaucoma. Ophthalmology. 2009; 116(6): 1097-1105. PMid: 19376591. http://dx.doi.org/10.1016/j.ophtha.2009.01.021

[3] Watson PG. When to operate on open angle glaucoma. Eye. 1987;
1(1): 51-54. PMid: 2881812. http://dx.doi.org/10.1038/eye .1987 .8

[4] Landers J, Martin K, Sarkiers N, et al. A twenty-year follow-up study of trabeculectomy: risk factors and outcomes. Ophthalmology. 2012; 119(4): 694-702. PMid: 22196977. http://dx.doi.org/10.10 16/j.ophtha. 2011.09.043

[5] Cairns JE. Trabeculectomy. Preliminary report of a new method. Am J Ophthalmol. 1968; 66(4): 673-9. http://dx.doi.org/10.1016 /0002-9394 (68)91288-9 
[6] Mastropasqua R, Fasanella V, Agnifili L, et al. Anterior segment optical coherence tomography imaging of conjunctival filtering blebs after glaucoma surgery. Biomed Res Int. 2014; 2014: 610623. PMid: 25136603. http://dx.doi.org/10.1155/2014/610623

[7] Kronfeld PC. Functional characteristics of surgically produced outflow channels. Transactions of the American Academy of Ophthalmology and Otolaryngology. 1969; 73(2): 177-193. http://dx.d oi.org/10.1016/0002-9394(69)94251-2

[8] Migdal C, Hitchings R. The developing bleb: effect of topical antiprostaglandins on the outcome of glaucoma fistulising surgery, British Journal of Ophthalmology. 1983; 67(10): 655-660. PMid: 6615751. http://dx.doi.org/10.1136/bjo.67.10.655

[9] Picht G, Grehn F. Classification of filtering blebs in trabeculectomy: biomicroscopy and functionality. Current Opinion in Ophthalmology. 1998; 9(2): 2-8. PMid: 10180508. http://dx.doi .org/10.1097 /00055735-199804000-00002

[10] Cantor LB, Mantravadi A, WuDunn D, et al. Morphologic classification of filtering blebs after glaucoma filtration surgery: the Indiana Bleb Appearance Grading Scale. Journal of Glaucoma. 2003; 12(3): 266-271. PMid: 12782847. http://dx.doi.org/10.1097/000 61198-200306000-00015

[11] Ciancaglini M, Carpineto P, Agnifili L, et al. Filtering bleb functionality: a clinical, anterior segment optical coherence tomography and in vivo confocal microscopy study. Journal of Glaucoma. 2008; 17(4): 308-317. PMid: 18552617. http://dx.doi.org/10.1097 /IJG.0b013e31815c3a19

[12] Mastropasqua L, Agnifili L, Mastropasqua R, et al. Conjunctival modifications induced by medical and surgical therapies in patients with glaucoma. Current Opinion in Pharmacology. 2013; 13(1): 56-64. PMid: 23127698. http://dx.doi.org/10.1016/j.coph. 2012 .10 .002

[13] Carpineto P, Agnifili L, Nubile M, et al. Conjunctival and corneal findings in bleb-associated endophthalmitis: an in vivo confocal microscopy study. Acta Ophthalmologica. 2011; 89(4): 388-395. PMid: 19900202. http://dx.doi.org/10.1111/j.1755-3768. 2009.01767.x

[14] Ciancaglini M, Carpineto P, Agnifili L, et al. Conjunctival characteristics in primary open-angle glaucoma and modifications induced by trabeculectomy with mitomycin $\mathrm{C}$ : an in vivo confocal microscopy study. British Journal of Ophthalmology. 2009; 93(9): 1204-1209. PMid: 19570768.http://dx.doi.org/10.1136/bjo.2008.15 2496
[15] Shimeles A. Community Based Health Insurance Schemes in Africa: the Case of Rwanda. African Development Bank Group. Working Paper. 2010; 120. PMid: 24138894. http://dx.doi.org/10.10 16/j.survophthal.2013.06.005

[16] Mastropasqua L, Agnifili L, Salvetat ML, et al. In vivo analysis of conjunctiva in canaloplasty for glaucoma. British Journal of Ophthalmology. 2012; 96(5): 634-639. PMid: 22296832. http: //dx.doi.org/10.1136/bjophthalmol-2011-301058

[17] Mastropasqua L, Agnifili L, Ciancaglini M, et al. In vivo analysis of conjunctiva in gold micro shunt implantation for glaucoma. British Journal of Ophthalmology. 2010; 94(12): 1592-1596. PMid: 20805134. http://dx.doi.org/10.1136/bjo.2010.179994

[18] Mastropasqua L, Agnifili L, Mastropasqua R, et al. In vivo laser scanning confocal microscopy of the ocular surface in glaucoma. Microscopy and Microanalysis. 2014; 20(3): 879-894. PMid: 24576766. http://dx.doi.org/10.1017/S1431927614000324

[19] Mastropasqua R, Fasanella V, Pedrotti E, et al. Transconjunctival aqueous humor outflow in glaucomatous patients treated with prostaglandin analogues: an in vivo confocal microscopy study. Graefe's Archive for Clinical and Experimental Ophthalmology. 2014 PMid: 24867312. http://dx.doi.org/10.1007/s00417-014 $-2664-9$

[20] Singh M, See JL, Aquino MC, et al. High-definition imaging of trabeculectomy blebs using spectral domain optical coherence tomography adapted for the anterior segment. Clin Experiment Ophthalmol. 2009; 37(4): 345-51. PMid: 19594559. http://dx.doi.org/10. 1111/j.1442-9071.2009.02066.x

[21] Abrams GW, Thomas MA, Williams GA, et al. Management of postoperative suprachoroidal hemorrhage with continuous-infusion air pump. Archives of Ophthalmology. 1986; 104(10): 1455-1458. PMid: 3490249. http://dx.doi.org/10.1001/archopht.1986.010 50220049024

[22] D'Ermo F, Bonomi L, Doro D. A critical analysis of the long term results of trabeculectomy. American Journal of Ophthalmology. 1979; 88(5): 829-835. http://dx.doi.org/10.1016/0002-9394(79 ) $90559-2$

[23] Levene RZ. Glaucoma filtering surgery: factors that determine pressure control. Ophthalmic Surgery. 1984; 15(6): 475-483. PMid: 6462607.

[24] Levene RZ. Glaucoma filtering surgery factors that determine pressure control. Transactions of the American Ophthalmological Society. 1984; 82: 282-301. PMid: 6535327. 